\title{
STATISTICAL PREDICTORS OF HAZARDOUS MEDICAL WASTE GENERATION RATES IN A 40-BED GENERAL HOSPITAL
}

\author{
D. KOMILIS ${ }^{1 *}$ \\ N. KATSAFAROS ${ }^{2}$
}

\author{
${ }^{1}$ Laboratory of Solid and Hazardous Wastes \\ Department of Environmental Engineering \\ Democritus University of Thrace \\ Xanthi, 671 00, Greece \\ ${ }^{2}$ Municipality of Ikaria
}

Received: 05/01/11

Accepted: 30/03/11 *to whom all correspondence should be addressed: e-mail: dkomilis@env.duth.gr

\begin{abstract}
Objective of the work was to investigate correlations among hazardous medical waste generation rates and various hospital parameters in 2 departments and a clinic of a 40-bed Hellenic general hospital (Hospital of Ikaria). Medical waste was recorded at the bio-pathology lab, the pathology clinic and the emergency department 4 times daily during a 42 sampling day period (from December 2008 to May 2009). The hospital parameters recorded on a daily basis were the number of examinees, the number of patients that occupied beds and the number of tests performed daily at the clinical bio-pathology laboratory. The dependent variable was the medical waste generation rate $\left(\mathrm{kg} \mathrm{day}^{-1}\right)$ in all cases. Statistically significant linear correlations were established in all departments; the strongest correlation $\left(\mathrm{R}^{2} \approx 0.75\right)$ was calculated at the clinical bio-pathology laboratory and the weakest $\left(R^{2}=0.30\right)$ at the emergency department. An analysis of variance (Tukey's t-test) and a nonparametric statistical test revealed that medical waste generation rates from the clinical biopathology laboratory were statistically lower in the weekends compared to weekdays. In addition, medical waste amounts generated by the pathology clinic were statistically lower during December and January compared to February and April.
\end{abstract}

KEYWORDS: medical waste, health care waste, correlation, analysis of variance, t-test.

\section{INTRODUCTION}

Based on Greek legislation (HMWC, 2003), medical waste (MW) is the waste produced from medical facilities which is included under chapter 18 of the European Waste Catalogue (EWC). According to HMWC (2003), MW is classified into: a) Household type medical waste, which have similar properties to household solid waste, and, b) Hazardous medical waste (HMW), which is further classified into: i) waste with solely infectious properties (e.g. body tissues, blood, fecal and urine samples from patients with an infectious disease, needles etc.), ii) waste with both infectious and toxic properties (e.g. chemotherapy related waste, waste from bio-pathology and histology laboratories etc.), iii) waste with solely toxic properties (e.g. waste that contain mercury, hazardous organic waste, expired drugs, filters etc.), iv) Other types of medical waste (e.g. radioactive waste, batteries, pressurized cans etc.).

Variable definitions of medical waste exist among countries. This may partly explain the wide differences among the medical waste generation rates obtained by various researchers worldwide (Komilis et al., 2011). For example, Bdour et al. (2007) never used the term hazardous medical waste in their study; they classified medical waste into pathological waste, sharps and infectious waste. Cheng et al. (2009) classified medical waste into infectious waste and general medical waste without clearly defining, however, these 2 categories.

The assessment of medical waste composition and the quantification of their rates of generation is a popular research area recently. Many researchers pursue the development of equations to describe and predict MW generation rates as a function of key hospital parameters, such as the number of examinees, patients, occupied beds, official beds, number of doctors, etc. Such equations can have 
major practical significance, since they can be readily used for the prediction of hazardous medical waste generation rates from a medical facility without the need to perform costly measurements at the source. Such information is necessary during the design of MW transfer and treatment systems.

Several authors have attempted to establish linear relationships among MW generation rates and several hospital related parameters (independent variables). Bdour et al. (2007) found a relatively high statistically significant (linear) correlation between the number of patients and the amount of MW generated daily. A lower statistically significant correlation (with a linear trend visually evident) was calculated between the number of beds and the MW generated per day (Bdour et al., 2007). Cheng et al. (2009) found that the amounts of infectious waste generated by several medical facilities in Taiwan were marginally correlated to the number of hospital beds $($ at $p<0.05)$. Sanida et al. (2010) calculated correlations among the amounts of HMW generated daily and several parameters, such as the number of occupied beds, medical tests per day, nurses, surgeries per day and hospital employees (authors included the relevant scatter-plots in an Appendix). Although statistically significant coefficients of determination $\left(R^{2}\right)$ were calculated in all above cases, the correlations were actually weak, as was judged by the visual interpretation of the data. All relatively high $\mathrm{R}^{2}$ coefficients calculated by Sanida et al. (2010) were actually "governed" by two extreme values; all other data clustered at the left bottom part of the graphs without the presence of a discernible trend. That is, the large range of variation of the independent variables inevitably led to the misleadingly high $\mathrm{R}^{2}$ values; however, this is not an indication of a good correlation (Berthouex and Brown, 2002). Graikos et al. (2010) calculated a relatively low correlation between the HMW generated and the number of patients in a surgery department of a small Hellenic medical facility in Xanthi. No correlation plots were, however, presented to better evaluate the strength of the correlations, which were judged solely by the magnitude $(<0.3)$ of the linear $R^{2}$ coefficient. Conclusively, it appears that researchers still seek reliable predictors of medical waste generation rates in hospitals.

Objective of this work was to investigate the potential correlation of various hospital parameters with the hazardous medical waste generation rates from 2 departments and a pathology clinic at the General Hospital of Ikaria. The definition of HMW in this work was based on the pertinent Greek legislation (HMWC, 2003), as described earlier. Linear statistical models were developed for each of the departments of the aforementioned hospital. The pertinent correlation plots were included, since the graphical illustration of the data is of key importance when interpreting correlations. An analysis of variance was also performed to investigate statistically significant temporal variations of the HMW generation rates within each department during the 6 month sampling period.

\section{MATERIALS AND METHODS}

The methodology of data acquisition at the hospital of Ikaria is described in detail in Komilis et al. (2011). In summary: Medical waste was weighed separately at each of the four departments of the hospital, namely: the patients' room (pathology clinic), the clinical bio-pathology laboratory (CBPL), the emergency department (ER) and the $X$-ray department. The measurement period was from December 2008 to May 2009. One full week (7 d) was randomly selected from each month. Weight measurements were performed daily over 6 full weeks (from Monday to Sunday) of the above period, so that the sample size was 42 days. Statistical analysis was performed with MINITAB ${ }^{\circledR}$ Release 15

\section{RESULTS AND DISCUSSION \\ Medical waste generation rates}

The unit hazardous medical waste generation rates from the hospital of Ikaria are presented and discussed in detail in Komilis et al. (2011). In summary, the average HMW generation at the pathology clinic was $0.66 \mathrm{~kg}$ occupied bed ${ }^{-1}$ day $^{-1} \pm 27 \%$. The emergency department had the next highest average HMW generation rate, which was $0.26 \mathrm{~kg}_{\text {patient }}{ }^{-1}$ day $^{-1} \pm 50 \%$. The clinical biopathology laboratory produced an average of $0.069 \mathrm{~kg}^{\text {examine }} \mathrm{e}^{-1}$ day $^{-1} \pm 90 \%$ and $0.014 \mathrm{~L}$ of liquid waste examinee ${ }^{-1}$ day $^{-1} \pm 80 \%$. The X-ray lab produced an average of $0.083 \mathrm{~L}_{\text {examine }}{ }^{-1}$ day $^{-1}$. The combined HMW generation rate from all departments and the pathology clinic was $1.2 \mathrm{~kg}$ occupied bed $^{-1}$ day $^{-1}$ and $0.33 \mathrm{~kg}$ official bed ${ }^{-1}$ day $^{-1}$ (Komilis et al., 2011). The unit HMW generation rates calculated from the hospital of Ikaria were lower than, but yet comparable to, the HMW amounts measured in other Hellenic hospitals (Tsakona et al., 2007; Sanida et al., 2010). 


\section{Correlations}

Figure 1a illustrates the daily amounts of solid and liquid HMW generated by the clinical biopathology laboratory versus the total number of examinees per day. Figure $1 \mathrm{~b}$ illustrates the correlation of HMW generated vs the (combined) number of biochemical, immunological, haematological and urine analysis tests. According to Figure 1, there were clear linear trends in all 3 cases. Figure 2 illustrates the correlation between the amounts of (solid) HMW generated by the emergency department and the number of examinees per day at that department. A linear trend is also evident, though the correlation is not as strong as in the case of the CBPL $\left(R^{2}=0.30\right)$. Yet, it is a statistically significant correlation. Figure 3 is a correlation plot between the daily amounts of (solid) HMW generated and the average daily number of patients that occupied beds in the pathology clinic. A linear trend is evident here, too, with a calculated (statistically significant) $R^{2}$ equal to 0.43 . Therefore, the number of beds occupied daily in the pathology clinic can be used as a predictor of HMW generation rates in the hospital of Ikaria.

All lines in Figures 1 to 3 were fitted without an intercept. This was based on the notion that no HMW is expected to be generated by a department (or laboratory) that has no patients or examinees. Particularly in the case of Figure 1a, if intercepts were calculated, they would have been negative values, which can be hardly explained. On the other hand, the intercepts of the linear equations of Figures 1b, 2 and 3 would have been positive values. No intercepts were eventually fitted, since there were no records of HMW generated by an empty department.

All $R^{2}$ coefficients of the above linear equations were statistically significant at $p<0.05$; in addition, the linear parameters in all 5 models were statistically significant (at $p<0.005)$ as well, as can be also judged by the magnitude of the standard errors (values in parentheses) of these parameters. The residuals of all 5 linear models were distributed normally with a zero mean, indicating the validity of the models. Finally, based on the graphical illustration of the data, all 5 correlations can be rendered acceptable (despite the variability in the $R^{2}$ values), since data were distributed uniformly within the range of variation of the independent variables. This is a necessary condition in order to justify the "good quality" of a correlation regardless of the magnitude of the $\mathrm{R}^{2}$ coefficient (Berthouex and Brown, 2002).

Apparently, the strongest correlations were achieved at the CBPL with $\mathrm{R}^{2}$ coefficients approximately equal to 0.75 in all cases. It is worth noting that negligible HMW (solid and liquid) generation rates (ranging from 0.004 to $0.018 \mathrm{~kg} \mathrm{day}^{-1}$ ) were recorded at the CBPL during the 12 weekend days (not clearly shown in Figure 1a due to overlapping of the data points), despite the fact that between 2 to 9 examinees visited that department during those days. According to the CBPL personnel, the solid waste generated during weekend days were not wasted at the end of these days, but were stored and discarded on the Mondays that followed. Liquid waste generated by the CBPL was, however, still wasted to the sink during those days.

As is evident from the linear parameters (slopes of lines) of the equations in Figures 1 to 3 , the following predictors of HMW generation rates can be established: $0.64 \mathrm{~kg}_{\text {patient }}{ }^{-1}$ day $^{-1}$ or kg occupied bed ${ }^{-1}$ day $^{-1}$ at the pathology clinic, $0.24 \mathrm{~kg}_{\text {examinee }}^{-1}$ at the ER and $0.11 \mathrm{~kg}$ of (solid and liquid) HMW examinee ${ }^{-1}$ at the CBPL. It is interesting to note that Sanida et al. (2010), based on their study of 9 large general hospitals in Central Macedonia, calculated a "slope" of $1.058 \mathrm{~kg}$ of infectious waste patient ${ }^{-1}$ day $^{-1}$ or kg occupied bed ${ }^{-1}$ day $^{-1}$. According to Figure $1 \mathrm{~b}, 0.044 \mathrm{~kg}$ of HMW was generated, on average, per test performed in the clinical bio-pathology laboratory. Interestingly, Sanida et al. (2010) calculated $0.0061 \mathrm{~kg} \mathrm{test}^{-1}$ from the 9 large general hospitals in Central Macedonia.

Based on the aforementioned statistical correlations, the number of examinees, number of patients that occupy beds and the daily number of clinical tests were statistically significant predictors of HMW generation rates at the hospital of Ikaria. It would be worthwhile to perform similar research projects in departments of hospitals of similar sizes in order to check the validity and reproducibility of the equations. 


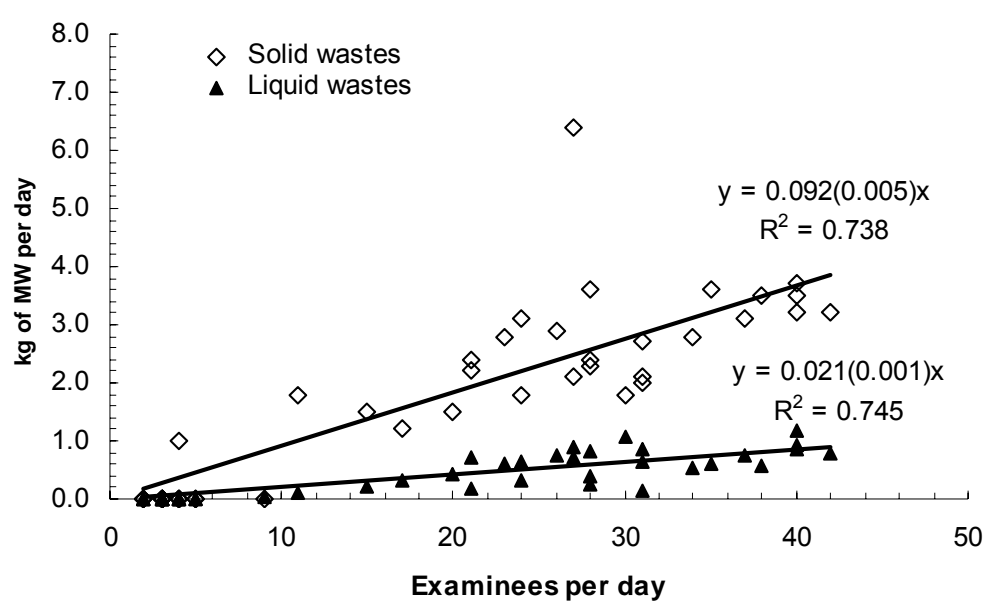

(a)

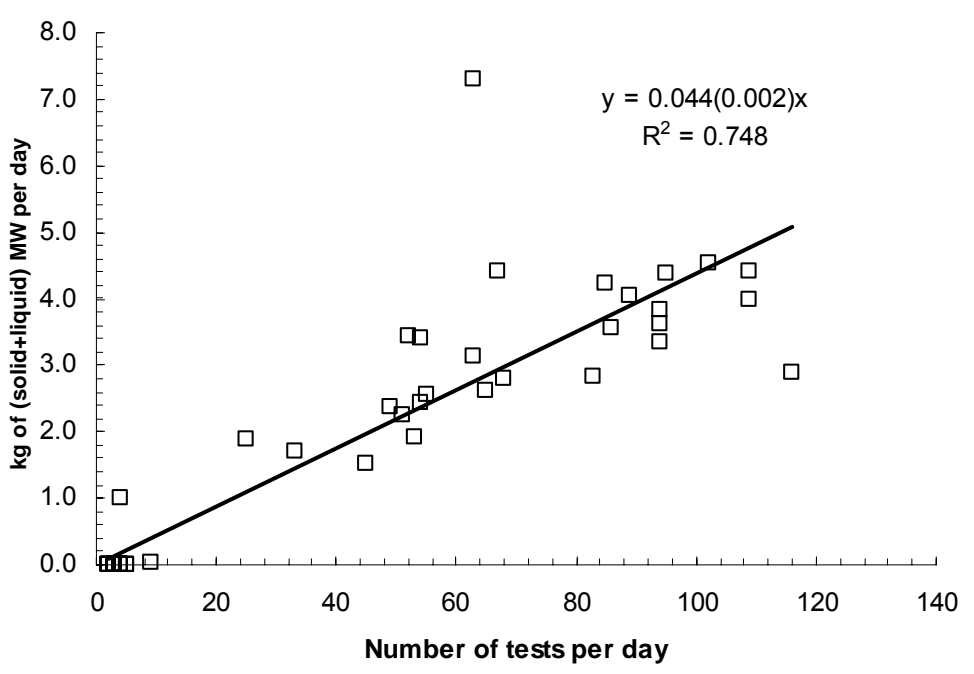

(b)

Figure 1. (Solid and liquid) HMW daily generation rates at the clinical bio-pathology laboratory: (a) versus number of examinees per day, (b) versus number of tests performed daily. Values in parentheses are the standard errors of the linear parameters.

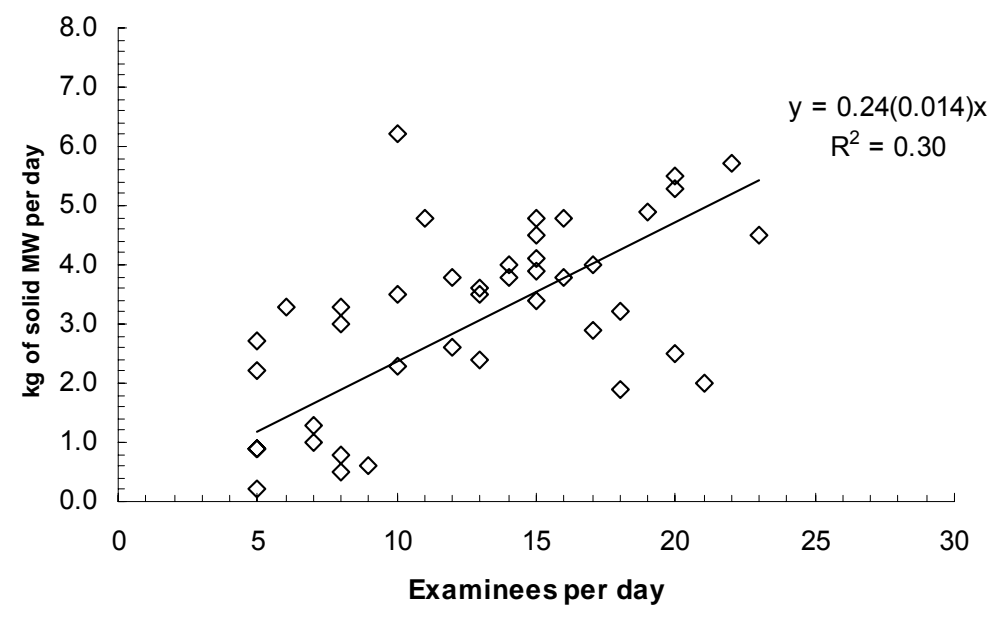

Figure 2. (Solid) HMW daily generation rate at the emergency department. Value in parenthesis is the standard error of the linear parameter 


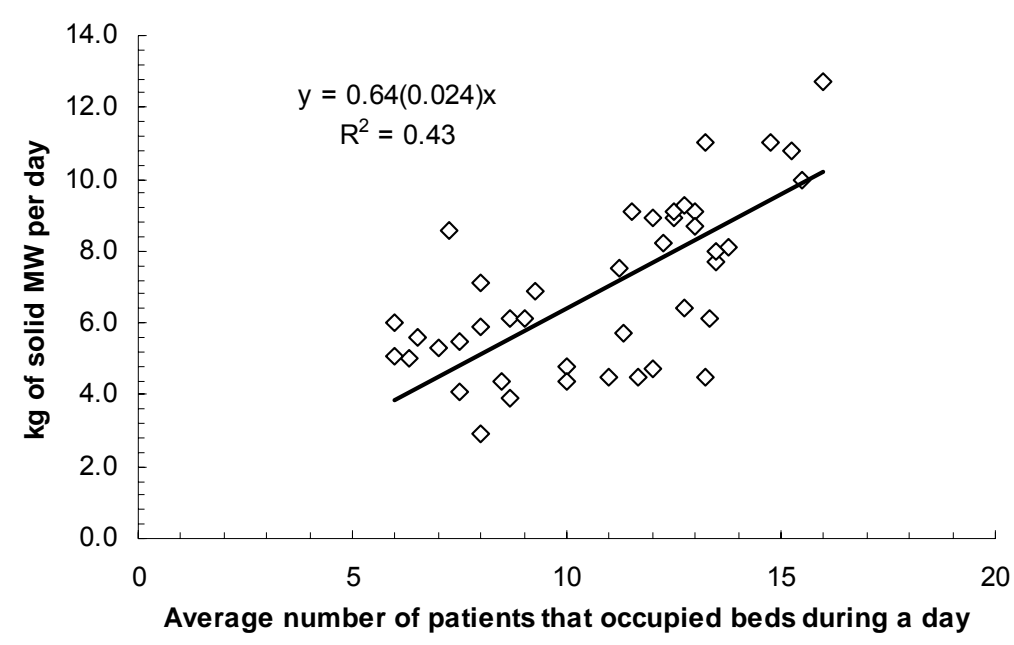

Figure 3. (Solid) HMW daily generation rate at the pathology clinic. Value in parenthesis is the standard error of the linear parameter

\section{Temporal variations}

According to Komilis et al. (2011), monthly average HMW generation rates varied from 0.50 (December) to $0.84 \mathrm{~kg}_{\text {patient }}{ }^{-1}$ day $^{-1}$ (April) in the clinic, from 0.19 (February) to $0.32 \mathrm{~kg} \mathrm{patient}^{-1}$ day $^{-1}$ (December) in the ER and from 0.046 (December) to 0.099 (January, May) combined solid and liquid $\mathrm{kg}$ of HMW examinee ${ }^{-1}$ day $^{-1}$ in the CBPL. Statistical analyses (Tukey's pair-wise t-test and a non-parametric test) were performed on the 42 daily measurements to investigate temporal variations among days within a week and among months at each of the 3 departments (CBPL, ER, pathology clinic). The Tukey's pair-wise t-test examines the confidence intervals of all potential pairwise differences of the means of the data and was performed according to Berthouex and Brown (2002). A condition is that data must be distributed normally. The non-parametric Kruskal-Wallis test does not assume a normality of the data and compares medians rather than means. Goal of the analyses was to deduce whether one month generated statistically different HMW amounts compared to another month, or whether certain days of a week generated statistically different HMW amounts compared to other days of the week. Both tests were performed at a 95\% confidence level.

According to Table 1, the HMW amounts generated on December and January were significantly lower compared to the HMW generation rates of February and April. The lower HMW generation rates of December can be likely explained by the fact that sampling took place on Christmas week. In addition, HMW generation rates of the CBPL on Saturdays and Sundays were statistically lower compared to the amounts generated on weekdays. This was an expected finding, since no solid medical waste was disposed of by the CBPL during the weekends, as mentioned earlier. No other temporal statistical differences were recorded in all other cases. The results of the non-parametric Kruskal-Wallis test were similar to that of the ANOVA (see Table 1).

Table 1. Statistically significant temporal differences based on Tukey's pairwise t-test and the non-parametric Kruskal-Wallis test (at a 95\% confidence level)

\begin{tabular}{|c|c|c|c|}
\hline $\begin{array}{c}\text { Hospital } \\
\text { department }\end{array}$ & $\begin{array}{l}\text { Parameter } \\
\text { examined }\end{array}$ & $\begin{array}{c}\text { Differences } \\
\text { among months }\end{array}$ & $\begin{array}{l}\text { Differences among } \\
\text { days of the week }\end{array}$ \\
\hline $\begin{array}{l}\text { Clinical bio- } \\
\text { pathology } \\
\text { laboratory }\end{array}$ & $\begin{array}{l}\mathrm{kg} \mathrm{examinee}_{\text {day }^{-1}}^{-1} \\
\text { ent }\end{array}$ & $\begin{array}{l}\text { No statistically significant } \\
\text { differences were calculated }\end{array}$ & $\begin{array}{l}\text { Saturdays and Sundays had } \\
\text { lower HMW generation rates } \\
\text { compared to all other days of the } \\
\text { week * }\end{array}$ \\
\hline $\begin{array}{l}\text { Emergency } \\
\text { department }\end{array}$ & $\begin{array}{c}\mathrm{kg}_{\text {day }^{-1}}^{\text {examinee }} \\
\end{array}$ & $\begin{array}{l}\text { No statistically significant } \\
\text { differences were calculated }\end{array}$ & $\begin{array}{l}\text { No statistically significant } \\
\text { differences were calculated }\end{array}$ \\
\hline $\begin{array}{l}\text { Pathology } \\
\text { clinic }\end{array}$ & $\mathrm{kg}$ patient ${ }^{-1}$ day $^{-1}$ & $\begin{array}{l}\text { December and January had } \\
\text { lower HMW generation rates } \\
\text { compared to February and April }\end{array}$ & $\begin{array}{l}\text { No statistically significant } \\
\text { differences were calculated }\end{array}$ \\
\hline
\end{tabular}

*: only liquid waste (from blood and urine analyses) was disposed of by the CBPL on weekend days 


\section{CONCLUSIONS}

Statistically significant linear correlations between the number of tests, number of examinees, number of occupied beds and the medical waste generation rates were calculated at the clinical biopathology lab, the emergency department and the pathology clinic. The strongest linear correlations $\left(R^{2} \approx 0.75\right)$ were established at the clinical bio-pathology laboratory. The weakest, yet statistically significant, correlation $\left(R^{2}=0.30\right)$ was established at the emergency department. All linear parameters in the equations presented were statistically significant at $p<0.005$.

Based on the aforementioned statistics and on the visual interpretation of the correlation plots, predictors of daily HMW generation rates at the pathology clinic, at the ER and at the CBPL were: $0.64 \mathrm{~kg}_{\text {patient }}{ }^{-1}$ day $^{-1}$ or kg occupied bed ${ }^{-1}$ day $^{-1}, 0.24 \mathrm{~kg}^{-1}$ examine $\mathrm{e}^{-1}$ and $0.11 \mathrm{~kg}$ (solid and liquid $\mathrm{HMW}_{\text {) examinee }}{ }^{-1}$, respectively. In addition, another predictor of HMW generation rate at the clinical bio-pathology laboratory was $0.044 \mathrm{~kg} \mathrm{test}^{-1}$.

The HMW generation rates from the clinical bio-pathology laboratory were statistically lower in the weekend compared to the generation rates during weekdays. In addition, the HMW generation rates from the pathology clinic were statistically lower during December and January compared to February and April. No other temporal variations were calculated.

\section{ACKNOWLEDGMENTS}

The authors wish to acknowledge Mr. A. Skaros, manager of the General Hospital of Ikaria at the time of the study, for his cooperation.

\section{REFERENCES}

Bdour A., Altrabsheh B., Hadadin N. and Al-Shareif M. (2007), Assessment of medical wastes management practise: A case study of the northern part of Jordan, Waste Management, 27, 746759.

Berthouex P.M. and Brown L.C. (2002), Statistics for Environmental Engineers and Scientists, $2^{\text {nd }}$ ed., CRC Press Ltd., Boca Raton, FL, USA, pp. 336-338.

Cheng Y.W., Sung F.C., Yang Y., Lo Y.H., Chung Y.T. and Li K.C. (2009), Medical waste production at hospitals and associated factors, Waste Management, 29, 440-444.

Graikos A., Voudrias E., Papazachariou A., losifidis N. and Kalpakidou M. (2010), Composition and production rate of medical waste from a small producer in Greece, Waste Management, 30, 16831689.

Hellenic Medical Waste Circular (2003), Measures and terms for the management of medical waste from medical facilities. No. 37591/2031/1419, Hellenic Printing Office, October (in Greek).

Komilis D., Katsafaros N. and Vassilopoulos P. (2011), Hazardous medical waste generation rates in Greece: Case studies from medical facilities in Attica and from a small insular hospital, Waste Management and Research, 29, 807-814.

Sanida G., Karagiannidis A., Mavidou F., Vartzopoulos D., Moussiopoulos N. and Chatzopoulos S. (2010), Assessing generated quantities of infectious medical wastes: A case study for a health region administration in Central Macedonia, Greece, Waste Management, 30, 532-538.

Tsakona M., Anagnostopoulou E. and Gidarakos E. (2007), Hospital waste management and toxicity evaluation: a case study, Waste Management, 27, 912-920. 